Etnográfica

Revista do Centro em Rede de Investigação em

Antropologia

vol. 22 (3) | 2018

Vol. 22 (3)

\title{
Dispositivo de saúde, manejo terapêutico e práticas de cuidado no Serviço Residencial Terapêutico
}

Health device, therapeutic management and care practices in Therapeutic

Residential Services

\section{Lecy Sartori}

\section{(2) OpenEdition}

\section{Journals}

Edição electrónica

URL: https://journals.openedition.org/etnografica/5914

DOI: 10.4000/etnografica.5914

ISSN: 2182-2891

\section{Editora}

Centro em Rede de Investigação em Antropologia

\section{Edição impressa}

Data de publição: 1 outubro 2018

Paginação: 555-574

ISSN: 0873-6561

\section{Refêrencia eletrónica}

Lecy Sartori, «Dispositivo de saúde, manejo terapêutico e práticas de cuidado no Serviço Residencial Terapêutico», Etnográfica [Online], vol. 22 (3) | 2018, posto online no dia 10 outubro 2018, consultado o 20 janeiro 2022. URL: http://journals.openedition.org/etnografica/5914 ; DOI: https://doi.org/10.4000/ etnografica. 5914

\section{(c) (i) (9)}

Etnográfica is licensed under a Creative Commons Attribution-NonCommercial 4.0 International License. 


\section{Dispositivo de saúde, manejo terapêutico e práticas de cuidado no Serviço Residencial Terapêutico}

\section{Lecy Sartori}

A partir de uma etnografia sobre as modificações decorrentes do processo de reforma no modelo de assistência psiquiátrica do Serviço de Saúde Dr. Cândido Ferreira (SSCF) no município de Campinas (SP), descrevo os arranjos técnicos e arquitetônicos que transformaram as moradias assistidas em um dispositivo de saúde. O ponto de partida são os efeitos do processo de reabilitação dos usuários que vivem no Serviço Residencial Terapêutico (SRT). Trata-se de analisar como a equipe do SRT organiza o modo de operar a assistência nas residências por meio da racionalização da singularidade do usuário em termos de necessidade e contextos de risco. Com isso, procuro expor os discursos que justificam a prática do manejo terapêutico e governo da vida dos moradores no SRT.

PALAVRAS-CHAVE: Serviço Residencial Terapêutico (SRT), etnografia, reabilitação, práticas de cuidado, manejo terapêutico.

Health device, therapeutic management and care practices in Therapeutic Residential Services - Based on an ethnography of the changes resulting from a reform process in the care model governing the psychiatric Health Service Dr. Cândido Ferreira (SSCF), in Campinas (Sao Paulo), I describe the technical and architectural arrangements that transformed residential assistance services into a health device. The starting point are the effects of the rehabilitation process of the users living in the Therapeutic Residential Services (SRT). I analyze how the SRT team organizes the assistance operations in the residences by rationalizing the user's singularity in terms of necessity and risk contexts, exposing the discourses that justify the therapeutic management and life governing practices provided to the residents in the SRT.

KEYWORDS: Therapeutic Residential Services (SRT), ethnography, rehabilitation, care practices, therapeutic management.

SARTORI, Lecy (lecysartori@gmail.com) - Universidade Federal de São Paulo (Unifesp), Brasil. 


\section{INTRODUÇÃO}

Neste artigo apresento os efeitos da reforma no modelo psiquiátrico do Serviço de Saúde Dr. Cândido Ferreira (SSCF), instituição que acompanho desde 2008. ${ }^{1}$ Argumento que as atualizações nas formas de "cuidado" produziram práticas de gestão dos "usuários" no Serviço Residencial Terapêutico (SRT). ${ }^{2}$ Para isso, descrevo como os meus interlocutores, os "profissionais" que trabalham no SSCF, explicam, por meio dos seus discursos mnemônicos, as estratégias políticas que resultaram em ações da reforma. Algumas dessas ações antecederam as normatizações ministeriais, como é caso das "moradias assistidas" (ou apenas "moradias", como afirmam alguns profissionais ao se referirem ao SRT). O foco do artigo recai sobre a racionalidade política que compõe as novas práticas de cuidado no SRT.

A reforma no modelo assistencial do SSCF foi atravessada pelo discurso do movimento da Reforma Psiquiátrica Brasileira (RPB), que questionou a forma de assistência médica psiquiátrica que se configurava em grandes instituições de confinamento (Silva 2013). Sabe-se que as contestações das práticas manicomiais no Brasil aconteceram mais intensamente no final da década de 1970, depois de denúncias contra ações desumanas - mortes não esclarecidas, estupros, agressões (Amarante 1995) - e a comprovação de que instituições manicomiais eram semelhantes a depósitos de pessoas em precariedade social (o mesmo que não possuir recursos financeiros e nem suporte familiar).

Lovell e Scheper-Hughes (1986) descrevem a desinstitucionalização como um processo de mudança no saber psiquiátrico que, em seus efeitos, provocou reconfigurações institucionais e a invenção de novas tecnologias gerenciais da loucura na Europa Ocidental e na América do Norte. Os americanos modernizaram a burocracia e o sistema médico de assistência após os questionamentos dos profissionais e dos pacientes acerca da legitimidade psiquiátrica. $\mathrm{Na}$ Itália, o movimento antimanicomial fundado pelo psiquiatra Franco Basaglia inspirou os profissionais a contestarem as técnicas de institucionalização da violência e os mecanismos que sujeitam os pacientes a aceitarem situações de

l Este artigo é uma versão modificada da primeira parte de minha tese de doutorado (Sartori 2015), defendida no Programa de Pós-Graduação em Antropologia Social da Universidade Federal de São Carlos. Aproveito para agradecer ao Prof. Jorge Villela, que me orientou, e os comentários de Ciméia Beviláqua, Cibele Rizek, Piero Lerner e Catarina Vianna. A pesquisa foi financiada pela Coordenação de Aperfeiçoamento de Pessoal de Nível Superior (Capes). Grande parte dos dados etnográficos descritos no artigo resultam de pesquisa de campo realizada entre os meses de março de 2011 e maio de 2012, nas reuniões de equipe do Serviço Residencial Terapêutico (SRT). Pela autorização de minha participação nos grupos institucionais, agradeço aos trabalhadores do SSCF, em especial, a Telma Palmieri (na época, presidente do seu Conselho Diretor).

2 As palavras e expressões entre aspas referem-se a termos nativos e se seguirão da explicação de seu significado. Os substantivos "usuário", "morador", "paciente", são termos acionados pelos meus interlocutores para se referirem às pessoas "cuidadas" em serviços do SSCF. 
opressão asilar. Basaglia, em uma série de seminários e conferências ministradas no Brasil, influenciou os rumos da reforma psiquiátrica no país.

Pode-se afirmar que não eram apenas os discursos médico e biológico da doença que justificavam a permanência da internação e o acionamento de uma política de assistência. No SSCF, a precariedade social, como uma condição socioeconômica, impediu a independência institucional de alguns "internos". Pessoas em situação de precariedade são descritas como vítimas das rupturas de suas relações (familiares, de amizade e de colegas de trabalho) e suscetíveis à pobreza. Além disso, análises epidemiológicas atestam que essa situação produz pessoas vulneráveis e propensas aos riscos de patologias. Segundo Fassin (2010), as vidas consideradas precárias são alvo de um governo humanitário. A razão humanitária compreende a dimensão de humanidade como uma condição compartilhada com outros seres humanos, o que resulta em uma demanda de direitos universais, e seu sentido está atado a um sentimento afetivo das pessoas por seus companheiros que tem como efeito a obrigação de assisti-los. Para o autor, a articulação entre a razão e a emoção define os sentimentos morais que são mobilizados nas ações políticas fabricadas a partir de uma linguagem de valor e de afetos, as quais legitimam as práticas de governo humanitário (Fassin 2010: 9). Ao descrever como a relação de "vínculo" no SRT é permeada por sentimentos e emoções, meu objetivo não foi analisar a razão humanitária, mas a forma como os elementos da subjetividade e da vida dos usuários são racionalizados e apreendidos como indicadores que justificam uma ação de cuidado. Aliás, a situação de precariedade é um risco que deve ser antevisto e evitado por meio de um cálculo racional e das intervenções dos profissionais.

Na década de 1990, os profissionais do SSCF investiram na "reabilitação" dos internos (Sartori 2017). A reabilitação ou ressocialização configura-se por ações que buscam auxiliar, prevenir ou reduzir as incapacidades e/ou dificuldades que são associadas à desordem mental. Investido sobre os "internos" do hospital psiquiátrico do SSCF, os impactos do processo de reabilitação resultaram na produção de subjetividade tanto daqueles como dos "profissionais". No caso destes, a intenção foi capacitá-los para a ação neste novo contexto de práticas externo ao hospital. No caso dos internos, o objetivo foi transformá-los em sujeitos ou moradores, ensinando as atividades de vida diárias, o cuidado com a higiene pessoal, responsabilizando-os por sua saúde e pela administração de suas medicações e, assim, elaborando um contexto de possibilidade para que eles produzissem a sua "autonomia" ou a independência dos cuidados institucionais para viver nas moradias.

Neste artigo, não pretendo expor a história do processo de reabilitação decorrente da RPB (como bem o fizeram Lougon 1987; Canesqui 2003; Carvalho 2014; Venâncio 1990; Cardoso 2002; Duarte 1986; Nakamura 2014; Dias 2007; Policarpo 2013; Monnerat 2011; Pitiá e Furegato 2009; Andrade e 
Maluf 2016; Portugal, Nogueira e Hespanha 2014). Minha ideia é apresentar de forma breve as mudanças que resultaram da reforma ocorrida no SSCF, para, em seguida, destacar o modo como funcionam as práticas de "cuidado" em suas "moradias assistidas". De fato, não proponho explorar as críticas ao processo de RPB (como bem o fizeram Siqueira-Silva, Nunes e Morais 2013), mas analisar como as configurações atuais das práticas de cuidado transformaram as moradias em um "serviço de saúde".

A relação de cuidado no SRT se aproxima da atividade de assistência individual e domiciliar como a relação de personal care ou "atenção pessoal" (Zelizer 2012). Hirata e Guimarães (2012) definem care como um sentimento de preocupação com as necessidades do outro. A partir dos dados da pesquisa etnográfica com os profissionais do SRT, descrevo o funcionamento de práticas de cuidado que combinam saberes (clínicos, psicológicos e assistenciais) na operacionalização da intervenção no território e nas residências dos "usuários". Ao transferirem as práticas de cuidados para as residências, as moradias deixam de ser apenas espaços de habitação e são consideradas um "dispositivo de saúde", ao oferecer a assistência clínica que aciona tanto os cuidados referentes aos problemas crônicos da velhice (diabetes, hipertensão, dificuldades de locomoção) como as intervenções que promovem a reabilitação psicossocial (manutenção de relações familiares; acompanhamento das relações de consumo; monitoramento das relações entre os moradores; estímulo à participação em atividades de lazer, esporte, arte e educação). ${ }^{3}$ No SRT, o cuidado é elaborado a partir da singularidade dos usuários, articulando procedimentos e saberes em intervenções de acompanhamento (controle contínuo), monitoramento (vigilância a distância) e "manejo", com o objetivo de governar a conduta e o projeto de vida dos usuários.

A prática do "manejo" refere-se a ações calculadas para dirigir e orientar o comportamento dos usuários, a vida destes em liberdade. A noção de manejo é similar à de governo de Foucault (201 la: 53, 2006: 303), descrito como uma estratégia, um mecanismo, um procedimento para dirigir os homens; suas táticas compõem o Estado e acionam dispositivos de segurança para avaliar os custos, administrar os riscos, antever os acontecimentos e controlar a população, que se transforma em alvo das políticas (Foucault 2006: 303). Tendo por base a sua concepção de "governo", descrevo uma situação apresentada por uma interlocutora de pesquisa que atesta como são acionados os mecanismos de segurança nas práticas de cuidado, de acompanhamento e de monitoramento dos usuários no espaço da cidade, sua relação com a comunidade e com o comércio local. Observa-se que as intervenções buscam prevenir os riscos

3 A expressão "dispositivo de saúde”, ou apenas "dispositivo", era recorrente na fala dos profissionais quando se referiam aos serviços que compunham a rede de assistência do SSCF. Algumas interlocutoras afirmaram que a definição de “dispositivo” era a mesma descrita por Foucault (2004b: 244). 
por meio da gestão dos usuários nas moradias e de práticas de governo que direcionam as necessidades e desejos daqueles para os objetivos da reabilitação psicossocial.

O texto está dividido em cinco partes. Primeiramente, apresento o meu campo de pesquisa para, em seguida, descrever as modificações arquitetônicas que atualizaram a ideia de instituição, ao transformar o hospital psiquiátrico em uma rede composta por serviços situados no território. Na terceira parte, explicito as mudanças na relação de cuidado, a composição da equipe do SRT e como as moradias se tornaram um dispositivo de saúde. O deslocamento dos "internos" para as moradias foi efeito do rearranjo da equipe para conseguir formular intervenções em um novo espaço terapêutico, as residências dos usuários. Trata-se de verificar como são operadas as intervenções que em seus objetivos buscam o governo das condutas ou o manejo dos usuários nas moradias, assunto descrito na quarta parte. No último ponto, demonstro como as práticas de cuidados são formuladas a partir das singularidades, necessidades e desejos dos usuários. A partir disso, descrevo como o "manejo terapêutico" é avaliado como efetivo em seus resultados quando observa-se que os usuários se aliam ao discurso da "qualidade de vida" e seguem os direcionamentos da equipe de "moradias".

\section{ETNOGRAFIA}

Meu primeiro contato com o campo foi travado na pesquisa de mestrado que realizei em 2008, após a aprovação institucional do meu projeto e com a autorização da equipe do Centro de Atenção Psicossocial (CAPS) Esperança, que me permitiu participar diariamente das atividades por quatro meses. Nessa época, interessava-me entender como se configuravam as práticas de cuidado indicadas para as pessoas que, num passado recente, seriam confinadas em manicômios. Decerto, esse meu interesse foi instigado pelas leituras da disciplina "Poder, Política e Subjetividade" e por autores como Foucault, Nietzsche e Deleuze. Já em campo, procurava entender por meio de conversas com os profissionais do CAPS, o funcionamento institucional e a ideia de mudança da forma de cuidado. A sensação da mudança das práticas, recorrente no discurso dos profissionais, era explicitada por meio de exemplos que comparavam o tratamento do hospital psiquiátrico e o cuidado terapêutico empreendido por novos serviços que compunham a rede de assistência. ${ }^{4}$ Em suas falas, meus interlocutores afirmavam que as mudanças nas práticas foram influenciadas pelo processo de RPB.

4 Em 2012, a Rede de Atenção Psicossocial (RAPS) do SSCF era composta por instituições como o Núcleo de Retaguarda, o Núcleo de Oficinas e Trabalho (NOT), o SRT, três CAPS III, dois CAPS Álcool e outras Drogas (CAPSad), dois CAPS Infanto-Juvenil e três Centros de Convivências. 
A reforma no modelo de assistência psiquiátrica do SSCF tem algumas especificidades, como as mudanças colocadas em prática na década de 1990 sem o respaldo financeiro do Governo Federal, que foi normatizado em portarias ministeriais apenas na década subsequente. As mudanças mais visíveis se referem ao processo de "humanização", que implicava na reforma dos espaços de confinamento manicomial para proporcionar um local de habitação, e mesmo de morte, que fosse higiênico e confortável para os "internos"; na extinção progressiva de práticas violentas, quando usadas para punir os pacientes (cela forte, camisa de força, lobotomia e eletrochoque); em modificações no ambiente hospitalar, que produziram, entre outras coisas, a extinção da separação dos pacientes por gênero e a instauração de novas formas de intervenção terapêutica. ${ }^{5}$

No ano de 1990, os profissionais do SSCF elaboraram um projeto de moradias assistidas para abrigar os "internos" que viviam em seu hospital psiquiátrico. O "lar abrigado" foi a primeira moradia extra-hospitalar: criado em dezembro de 1991, abrigou seis "pacientes" autônomos. A "pensão protegida", a segunda moradia, foi implantada, em 1994, em uma das alas do hospital, adaptada em sua arquitetura para que os "internos" pudessem experimentar viver como em uma casa, aprender (ou reaprender) a cozinhar, organizar o seu quarto e os seus objetos pessoais (Rolim 2013; Furtado 2001). A terceira moradia foi inaugurada pela "equipe" da Unidade de Reabilitação dos Moradores (URM) em 1995, e abrigou nove "internos" menos autônomos ou que precisavam de cuidados intensivos ou um acompanhamento contínuo. Na segunda metade da década de 90, ocorreu o que os meus interlocutores chamam de "projeto de expansão do número de moradias": a implementação de mais 14 residências, o que des-hospitalizou grande parte dos "internos" do SSCF. Nessa época, o objetivo das práticas não era mais a reprodução da ala hospitalar, o encerramento manicomial, a cura dos transtornos mentais ou os tratamentos coletivos e disciplinares (que produzem cronificação e perda de autonomia). ${ }^{6}$ De forma geral, para que a reforma fosse possível, os profissionais investiram em ações

5 A "humanização", segundo a Política Nacional de Humanização (PNH), é um jogo ético, estético e político, ao produzir responsabilidade, subjetividade e sujeitos implicados com a gestão do Sistema Único de Saúde (SUS). Segundo Ong (2005) as práticas de humanização não estão desconectadas das relações de poder e acionam intervenções nos "regimes de vida" (Collier e Lakoff 2005), ou seja, nos valores que estabelecem "como as pessoas devem viver".

6 Usuários crônicos apresentam restrições em sua vida que os tornam, em maior ou menor grau, dependentes de outras pessoas (para se alimentar, se vestir e circular pela cidade). Os profissionais acreditam que a cronificação é resultado da rotina hospitalar, dos longos períodos de confinamento. Venâncio (1993: 125) afirma que o saber psiquiátrico considera a cronicidade inerente à doença mental, resultado de práticas de isolamento asilar e decorrente do uso de altas dosagens de medicamentos. As práticas que tinham por efeito a cronicidade foram intensamente criticadas por movimentos como o da antipsiquiatria (Cooper 1973; Szasz 1978, 1979) e o da luta antimanicomial. 
de reabilitação dos internos e na produção da subjetividade daqueles, na intenção de capacitá-los para atuar nesse novo contexto de práticas.

Iniciei o doutorado, em 2010, com o objetivo de analisar os documentos institucionais do SSCF e descrever o seu processo de reforma. Impossibilitada de acessar os documentos, que são armazenados em uma empresa privada na cidade de São Paulo, recorri aos meus amigos do CAPS Esperança, na tentativa de conhecer alguns profissionais que trabalharam no SSCF na década de 1990. Foi em uma conversa que a psicóloga Elis ${ }^{7}$ - mestre em psicanálise pelo Instituto Clínico de Buenos Aires (ICdeBA) e que trabalhava no SRT - afirmou que poderia ser interessante acompanhar e analisar as moradias para entender o processo de transferência dos internos, a desativação do hospital como lugar de habitação e os efeitos da reforma na instituição.

Após ser autorizada por instâncias burocráticas e pela equipe das moradias, em junho de 2011 comecei a frequentar a reunião do SRT. Nesse primeiro momento, observei os aspectos do funcionamento da equipe que revelaram a institucionalização do SRT, ou a mudança da função das moradias, que deixaram de ser apenas um espaço de habitação para tornar-se um serviço de saúde. De forma geral, a equipe era composta por 136 funcionários, que assistiam 163 usuários em 29 moradias [diário de campo, setembro de 201 1]. Participei regularmente da reunião de equipe, como ouvinte, todas as terças-feiras depois do almoço, até maio de 2012.

A reunião acontecia em um antigo prédio, onde funcionou, até meados da década de 1990, a ala Paraíso do hospital psiquiátrico do SSCF, no distrito de Sousas, em Campinas. Após a desativação daquela, o espaço foi reformado: em seu interior foram dispostas as salas administrativas. A sala de reunião da equipe era grande, ocupada por carteiras escolares de madeira dispostas ao redor, continha uma escrivaninha e, na parede, um quadro branco, para anotações. O espaço acomodava umas 20 pessoas, e era utilizado para outras atividades e para as aulas da residência médica em psiquiatria da instituição.

$\mathrm{Na}$ primeira parte da reunião (coordenada por um dos profissionais) eram apresentados os informes (avisos, informações diversas) e, depois, as pautas estas gerando discussões mais demoradas, nas quais os profissionais buscavam organizar e sistematizar o processo de trabalho, encaminhar os impasses das ações terapêuticas, orientar as condutas e comportamentos nas residências e avaliar as intervenções de cuidado. As reuniões (como observou Comerford 2001: 149) são espaços de resolução e socialidade que promovem uma rede de relações que ultrapassa as estruturas institucionais formais. A partir dessa ideia é possível afirmar que a reunião da equipe é um espaço em que as conexões para a produção de um trabalho em rede são estabelecidas, um lugar de troca de experiências e de saberes, de discussão e de avaliação, de aprimoramento e

7 Para preservar a identidade dos meus interlocutores, utilizo nomes fictícios. 
de capacitação da atuação dos profissionais acerca da gestão da vida e da residência dos usuários. Os profissionais avaliam continuamente as suas formas de atuação e o funcionamento do serviço. A configuração atual das práticas de cuidado no SRT é um efeito dos arranjos arquitetônicos da reforma institucional do SSCF.

\section{ARRANJOS INSTITUCIONAIS}

O fechamento da ala Arco-Íris, a criação de novas moradias, a transformação do projeto Casa-Escola no Centro de Convivência Casa dos Sonhos e a criação do Centro de Convivência e Arte (atual Espaço das Vilas), no período de 1996 -2000 , foram acontecimentos que produziram uma nova maneira de pensar a instituição, que não se limitava mais ao espaço do hospital. A instituição, após a desintegração de sua arquitetura fixa, murada e fechada, é pensada como algo que transborda os limites territoriais do SSCF e considera o que está fora, a comunidade. Essa ideia está em consonância com o processo da reforma que, a partir de 1998, começou a projetar um plano de expansão do número de moradias, que se concretizaria entre 1999 e 2000 . Com o planejamento das ações, a instituição desativou a ala Paraíso, reorganizou os recursos humanos e procedeu à realocação dos recursos financeiros para os serviços alternativos à internação.

Para os profissionais que trabalhavam no SSCF na década de 1990, a reforma tinha por finalidade a des-hospitalização dos "internos" que moravam no hospital. Para esse fim, a assistência modificou-se, o hospital deixou de ser espaço de habitação para tornar-se um lugar de experimentação e aprendizado. O hospital psiquiátrico, antes da Reforma Psiquiátrica, era a única alternativa de abrigo para pessoas com transtornos mentais que não tinham condições econômicas, as quais permaneciam, até a morte, confinadas. Essa função era similar ao objetivo do hospital geral, que até o século XVII prestava assistência aos pobres, sendo um espaço de internamento, de espera da morte, e não uma instituição médica (Foucault 2004a: 101).

Se o hospital psiquiátrico tinha a mesma função de assistência e de espaço de morte, o que há de diferente na experimentação do processo de reabilitação dos internos no SSCF? Neste, além da mudança da finalidade do hospital, pois deixou de ser lugar de abrigo permanente para ser um "espaço protegido" para tratamento e acompanhamento dos usuários em períodos de crise, o processo de des-hospitalização dos internos provocou uma diferença de aprendizado, uma vez que os profissionais precisaram desenvolver a habilidade de lidar com as dificuldades que aqueles tinham em cuidar de si e de sua casa - observa-se que o foco do aprendizado não estava na observação das manifestações dos sintomas psiquiátricos, mas na ideia de ensiná-los e orientá-los para que pudessem viver nas moradias assistidas. Em decorrência dessa nova forma de experimentação e direcionamento da vida dos internos, os profissionais repen- 
saram as suas práticas, que tinham como meta a transferência deles para as moradias, e avaliaram os seus efeitos. Esse arranjo nas intervenções terapêuticas foi organizado de forma individual. Para que os profissionais não perdessem as informações sobre a singularidade de cada interno, para que houvesse o monitoramento e a avaliação das intervenções que visavam à sua reabilitação, foi criado, em 1997, o Projeto Terapêutico Individual (PTI).

O PTI é um documento que registra as informações pessoais, as institucionais (número do prontuário, equipe, "técnico de referência"), as avaliações psiquiátricas e as propostas terapêuticas. Esse mecanismo de inscrição que apreende as singularidades (o mesmo que individualidades ou idiossincrasias) torna os usuários cognoscíveis a partir dos elementos que podem ser comparáveis (como o antes e o depois das intervenções de cuidado), explorando suas potencialidades e variabilidades. Nesse processo de singularização, eles foram capturados por um regime de saber "psi" (psicologia, psicanálise, psicoterapias e psiquiatria) que possibilita o cálculo das subjetividades, dos desejos, das motivações e das necessidades clínicas (a exemplo, um quadro confusional pode ser efeito do desequilíbrio da diabetes ou um sintoma psiquiátrico). O cálculo torna inteligível a subjetividade em uma linguagem de governo que promove a sua gestão racional (Rose 2011: 145). Para Foucault (201 la: 53, 201 lb: 9), o governo é um procedimento estrategicamente formulado para conduzir a conduta dos indivíduos. Suas táticas acionam dispositivos de segurança para avaliar e administrar os riscos, antever os acontecimentos e controlar a população, que se transforma em alvo das políticas (Foucault 2006: 303). As práticas de governo procuram fazer com que o usuário responda às atividades projetadas a partir de suas singularidades. Uma interlocutora de pesquisa, psicóloga que trabalhou na URM, me disponibilizou alguns documentos do PTI que datam de 1998. Pude observar que esses documentos dispunham as atividades em metas a serem alcançadas - a exemplo, “até seis meses" (atividade física, estimular autocuidado, socialização e atividades de lazer), “de 6 a 12 meses" (adquirir autonomia, preparar para viver na moradia, localizar família) e "mais de 12 meses" (solicitar benefício, trabalho, aprender a usar o dinheiro, fazer compras).

A partir das informações descritas no PTI, os profissionais calculam como algumas ações, "já testadas no passado", têm a probabilidade de não se efetivar. Do mesmo modo, intervenções de cuidado avaliadas como efetivas são retomadas e atualizadas. Como o resultado de uma intervenção pode ser imprevisível, os profissionais monitoram, acompanham os usuários e, por vezes, modificam a intensidade, recuam ou, até mesmo, suspendem a intervenção para elaborar outra que seja mais eficaz. Por isso, o registro das informações é importante para compor o cálculo da intervenção de cuidado.

Os usuários foram orientados a participar da construção do seu PTI. Essa inversão, de interno para sujeito atuante (ou participativo), resultado das 
ações terapêuticas, é um efeito das intervenções dos saberes "psi”, não no sentido acadêmico, de explicações abstratas, mas em sua função de "tecnologia intelectual" (Rose 2011: 24) que torna visíveis as composições de vida dos usuários, por meio de suas próprias idiossincrasias e de suas relações consigo e com outras pessoas.

A portaria GM/MS n. ${ }^{o}$ 106/2000, formalizou o SRT como instituição e disponibilizou o financiamento para equipar as residências. ${ }^{8} \mathrm{Com}$ isso, o SSCF montou 12 moradias. Conforme afirmou a gerente de um Centro de Convivência e Arte, psicóloga que trabalhou no SSCF no início da década de 2000, esse período foi de intensa modificação institucional. Os pacientes mais complexos (menos autônomos ou que possuíam, além do diagnóstico psiquiátrico, patologias clínicas, em sua grande maioria idosos e/ou cadeirantes e/ou acamados) foram reabilitados. Cabe lembrar que a equipe da URM transmutou-se em equipe do CAPS Estação e deslocou-se do espaço do SSCF, em Sousas, para um prédio no centro de Campinas. Com a reorganização espacial das instituições e o aumento de usuários nos CAPS, os profissionais começaram a questionar a efetividade do acompanhamento dos moradores nas residências terapêuticas. Ao problematizar a assistência, avaliaram as dificuldades de deslocamento dos CAPS até elas. Assim, para evitar a desassistência daqueles, produziram outro arranjo institucional que resultou na criação da equipe, em outras formas de cuidado e na gestão dos usuários nas moradias.

\section{DA COMPOSIÇÃO DA EQUIPE À OPERACIONALIZAÇÃO DAS PRÁTICAS}

$\mathrm{Na}$ pesquisa de campo, observei como a equipe do SRT é formada por atores diversos organizados em três equipes: "fixa", "volante" e "técnica". A "equipe fixa" é formada por monitores e auxiliares de moradias ${ }^{9}$ que permanecem nas residências para ajudar os usuários no cuidado com sua higiene pessoal, na preparação dos alimentos e na limpeza da casa. A “equipe volante” é composta por técnicos de enfermagem que circulam entre as moradias para verificar os sinais vitais, conferir e administrar medicações, orientar e auxiliar os moradores em seu autocuidado, acompanhar consultas e exames, incentivá-los a se responsabilizarem pelas atividades da casa e de seu projeto de vida, identificar demandas e "manejar" as crises. A “equipe técnica”, por sua vez, é formada pelos profissionais graduados (psicólogos, terapeutas ocupacionais, enfermeiras, médicos) que produzem relatórios, acompanham e solicitam os benefícios, ${ }^{10}$ preenchem o documento de faturamento e elaboram o PTI, coordenam

8 Ver portaria do Ministério da Saúde GM/MS n. ${ }^{\circ}$ 106/2000, de 11 de fevereiro.

9 Profissional contratado pelo SSCF para realizar os serviços domésticos, preparar refeições e ajudar os usuários. Em campo, vi apenas mulheres nessa função.

10 Refiro-me ao Benefício de Prestação Continuada (BPC), no valor de um salário mínimo (Brasil 1993), e ao benefício do Programa de Volta para Casa (PVC), destinado aos pacientes que [continua] 
reuniões, produzem ações em articulação com outros serviços, supervisionam estágios, orientam o trabalho das equipes fixa e volante, acompanham, planejam e executam as atividades sociais, educativas, terapêuticas e esportivas dos moradores. Em decorrência do grande número de pessoas que compõe a equipe, é frequente ocorrerem situações de conflito. Os conflitos advêm de falhas na comunicação, da ausência de profissionais que acarretam o remanejamento da equipe, de problemas com a escala, de situações imprevisíveis que acabam mobilizando parte da equipe e desfalcando outras residências, ou da dificuldade no entendimento das funções de cada equipe.

A configuração da equipe tem por objetivo assegurar o objetivo institucional da reabilitação psicossocial por meio de intervenções de cuidado e do acompanhamento de usuários nas moradias. A equipe se desloca para as moradias e opera formas estratégicas de intervenção para conduzir os usuários na realização das "atividades de vida diária" (o mesmo que ajudar em suas dificuldades de se vestir ou preparar a sua alimentação e em sua circulação). A organização dos profissionais em equipe fixa, volante e técnica compõe uma rede dinâmica de comunicação que transmite as informações e as necessidades dos usuários, que são discutidas em grupo e acionadas na elaboração das intervenções, com a finalidade de evitar situações de risco nas moradias.

Os profissionais diziam que a criação da equipe das moradias esteve associada a uma necessidade local dos usuários, que estavam envelhecendo e, em decorrência, apresentavam-se mais dependentes de ajuda para efetuar as atividades do dia a dia, além de manifestarem com maior frequência quadros de patologias crônicas (diabetes, hipertensão, obesidade) que solicitavam acompanhamento e cuidados clínicos. Conforme afirmou Julia, enfermeira e gestora da equipe de moradias, sobre a demanda de cuidados intensivos,

"Devido ao envelhecimento, ao aumento e agravamento de comorbidades [duas ou mais patologias] associadas à doença mental, alto grau de dependência que esses moradores apresentam para a reabilitação de atividades cotidianas, percebemos que é maior a demanda por moradias 24 horas e a necessidade de qualificação da equipe de cuidados para lidar com intercorrências clínicas e psiquiátricas visando o aperfeiçoamento e a ampliação do olhar desses profissionais para a identificação de situações de riscos". ${ }^{11}$

estiveram internados por, no mínimo, dois anos em hospitais psiquiátricos, cujo valor era, em 2012, de 320 reais (ver Lei n. ${ }^{\circ}$ 8.742, de 7 de dezembro de 1993, disponível em: < http://www.planalto.gov.br/ ccivil_03/Leis/L8742.htm > e a Lei n. ${ }^{\circ}$ 10.708, de 31 de julho de 2003, disponível em < http://www. planalto.gov.br/ccivil_03/Leis/2003/L10.708.htm >, última consulta em outubro de 2018).

11 O SRT é composto por diferentes moradias, como as de alta complexidade (em que permanece um profissional na residência por 24 horas), com atenção parcial, com profissional/cuidador ou "referência". 
O envelhecimento dos usuários e o aparecimento de situações clínicas são fatores acionados para justificar a intensificação do acompanhamento das atividades de reabilitação. Essa nova demanda produziu a necessidade de otimizar a percepção dos profissionais realizada através da qualificação profissional. A equipe técnica organizou um curso de capacitação que visava tornar os profissionais das equipes fixa e volante aptos para reconhecer os riscos. A categoria de risco, segundo o ponto de vista dos meus interlocutores, está relacionada a um contexto, a uma situação, a uma ação ou a um estado do usuário que pode lhe ocasionar um dano. Quanto ao que pode ser uma situação de risco para o usuário: uma residência com degraus representa um contexto de risco de queda; no caso da manifestação de um sintoma psiquiátrico de delírio, ele perde o discernimento sobre a realidade e não consegue analisar o risco que há em sair para a rua (ser atropelado ou perder-se, por exemplo); no caso de uma "crise" psicótica em que o usuário manifesta ações agressivas, estas podem ser consideradas um risco para quem estiver próximo e para ele mesmo. ${ }^{12}$

Assim, mais interessante que listar as situações que podem ser consideradas de risco é descrever o que a análise do risco aciona no interior das práticas de cuidado - em outras palavras, entender como a categoria de risco faz funcionar e, ao mesmo tempo, justifica as práticas de segurança e de gestão dos usuários no SRT. Os espaços em grupo, as reuniões (semanais as de "equipe" e quinzenais as de "supervisão") e as passagens de plantão diárias são contextos em que os profissionais se organizam para solucionar as demandas das moradias (a exemplo: a necessidade de cuidado de um usuário que não está se sentindo bem decorrente de uma dor física ou de um sofrimento psíquico; a necessidade de acompanhar um usuário em uma consulta ou na realização de um exame; o agendamento do motorista para levá-lo até o hospital; o acompanhamento em uma visita aos seus familiares).

A organização e o planejamento das ações que serão realizadas nas moradias expõe como as práticas de reabilitação se tornaram contínuas por meio do "manejo terapêutico" cotidiano, que busca prevenir os riscos e acompanhar o usuário. A noção de manejo se refere às ações "calculadas" para dirigir e orientar o comportamento dos usuários, para administrar a sua vida em liberdade. A prática do manejo é uma forma de gerenciar e direcionar a vida dos usuários para os objetivos institucionais da reabilitação.

\section{O MANEJO DA REABILITAÇÃO PSICOSSOCIAL}

A composição da equipe foi pensada a partir da necessidade de uma forma de ação flexível para atuar no território onde se localizam as moradias. A organização

12 A "crise" (ou surto psicótico) é manifestada por meio dos sintomas da psicose: alucinações auditivas e/ou visuais, agitação e agressividade (Sartori 2010). 
em equipes fixa, volante e técnica forma uma linha de comunicação direta entre as moradias e o espaço em que a equipe se concentra no SSCF. Essa comunicação era realizada no encontro entre os profissionais ou pela mediação de uma tecnologia (telefone celular, mensagens, rádio Nextel, e-mail). Pode-se afirmar que a equipe monitoriza, por meio de um mapeamento das moradias, a distribuição dos usuários nas residências/território, as informações acerca da individualidade dos moradores e a identificação dos contextos de risco. A partir disso, os profissionais formulam o planejamento estratégico de suas ações e a identificação dos problemas de segurança. A situação de risco é calculada a partir de seus efeitos futuros, que mobilizam a equipe a analisar de forma antecipada um possível dano ao usuário. Quanto maior for o dano previsto pela equipe, maior será a intensidade de suas intervenções (acompanhamento contínuo/diário, intervenções mais diretas na residência, avaliações mais frequentes para calcular se as ações estão atingindo os objetivos esperados).

Em 2011 , em um evento organizado pela equipe das moradias para comemorar os 20 anos do SRT, assisti à apresentação de Vera (interlocutora de pesquisa, psicóloga e psicanalista winnicottiana que trabalha no SSCF há 15 anos) sobre o caso do usuário Olavo, identificado pela equipe em um contexto de risco, com excesso de peso e diabético. ${ }^{13}$ No depoimento de Vera, pode-se observar o funcionamento da equipe que produz intervenções, após considerar que a diabetes de Olavo era incontrolável. Após essa constatação, a equipe começou a investigar as causas desse descontrole e descobriu que ele ingeria, quando os profissionais não estavam por perto, alimentos com grande quantidade de açúcar e gordura. Conforme contou Vera, em 2012, Olavo era um senhor de 63 anos nascido no interior de São Paulo, que estudou até a sétima série, trabalhou como agricultor e na construção civil. Ele apresentou os primeiros sinais da doença entre os 16 e 18 anos, ao sentir que tinha (nas palavras dele) "problemas na cabeça, as mãos tremiam, escutava vozes, via bichos na parede e bebia". Ele foi internado em vários hospitais da região de Campinas. Em sua primeira internação no SSCF, em 1992, permaneceu por um mês e foi diagnosticado como esquizofrênico. Teve outra internação em 1993. Em janeiro de 1997 foi encaminhado para o "lar abrigado". Em 2004 mudou-se para uma moradia onde vivia sozinho.

A primeira estratégia de manejo da equipe foi retirar da residência todos os produtos que Olavo não poderia ingerir (como sorvete, fritura e doces). Mesmo tendo os profissionais explicado os danos que esses alimentos poderiam causar em sua saúde, ele resistiu a essa ação e "entrou em crise", manifestando sintomas/sentimentos de perseguição com relação à equipe. Como essa ação foi avaliada como não efetiva, a equipe se reuniu para elaborar uma 
nova estratégia. Vera sugeriu acompanhar Olavo em suas compras de supermercado, para orientá-lo sobre quais produtos poderia comer e as consequências da ingestão de alguns alimentos que poderiam agravar a sua diabetes. Vera tinha por objetivo apresentar outros produtos "mais saudáveis" que poderiam substituir aqueles que Olavo não podia mais comer. A equipe julgava necessário que o usuário participasse do processo de mudança, para conseguir sustentar esse novo hábito alimentar que "produzia saúde", ao invés de "agravar a sua doença”. Essa estratégia, além de mobilizar um discurso de prevenção que aciona a tática do "convencimento", "conscientização" e "sensibilização" (como observado por Tavares, Caroso e Santana 2015: 501), procura fazer dos usuários autores das ações que vão dirigir e controlar os seus hábitos alimentares (ou comportamentos).

Essa prática experimental no cotidiano das moradias necessita de profissionais capacitados para ouvir, enxergar e se autoavaliar para aperfeiçoar suas estratégias de cuidado. Essa forma de atuação do profissional é uma prática de governo que se materializa em ações que pretendem conduzir a conduta dos usuários, direcionando os seus hábitos alimentares. Essas estratégias são elaboradas a partir de informações sobre a individualidade dos usuários, considerando suas necessidades e desejos que, por vezes, são contrários aos objetivos institucionais, como no caso de Olavo, que não queria se alimentar de forma saudável. Como observaram Hirata e Cardoso, a relação entre ações de governo e os sujeitos governados "é conflitiva e ao mesmo tempo relacional, ou seja, construída de forma conjunta e articulada em meio a negociações e disputas sobre os objetivos e as maneiras de se governar" (2016: 100). Nesse jogo tático, os profissionais negociam e consideram os desejos dos usuários quando produzem suas ações de cuidado, conduzindo-os para a efetivação da meta institucional da reabilitação e da produção de saúde ao evitar o agravamento de sua doença. As práticas de governo são conectadas aos saberes "psi” pela noção de individualismo (Rose 2011 l: 64), noção que eles operacionalizam utilizando-se de uma tecnologia de planejamento e de regulação das existências e de suas singularidades.

\section{O GOVERNO DAS SINGULARIDADES}

O modo como a equipe opera e tece a malha institucional formada por diferentes profissionais que se deslocam para produzir o cuidado nas moradias expõe como as estratégias de intervenção são pensadas para evitar o agravamento de doenças crônicas e de sofrimentos psíquicos. Segundo os profissionais, ao prevenir os agravamentos (manifestados em sintomas que requerem ações mais invasivas, como exames de sangue, aumento da medicação e internações) é possível melhorar a "qualidade de vida" dos moradores. O discurso da "qualidade de vida" expõe as motivações (do Estado e/ou de organizações 
não governamentais) para agir por meio de estratégias de segurança. Essas ações têm como alvo uma parcela da população classificada como vulnerável, identificada como estando em uma situação de risco e/ou como agentes produtores de "risco" ou contágio (cf. Pussetti e Brazzabeni 201 l: 473). O índice da "qualidade de vida" permite calcular o bem-estar dos usuários e se as ações terapêuticas são efetivas, além de racionalizar a realidade e a tornar visível às problematizações e avaliações. Assim, os indicadores de "qualidade de vida" e de "precariedade social" são formas de codificar, em uma linguagem, as necessidades observadas localmente que justificam as intervenções de governo na vida dos usuários.

Ao invés de recorrer aos protocolos terapêuticos formulados a partir do diagnóstico, os profissionais acionam as categorias de sofrimento, necessidade e risco para elaborar e justificar a intervenção terapêutica. O discurso da necessidade é formulado a partir dos argumentos da autobiografia dos usuários, que, por sua vez, legitimam sua gestão como vítimas das desordens sociais (Fassin 2004: 238). Esse discurso é invocado para legitimar e reivindicar as intervenções como uma forma de produzir saúde e minimizar o sofrimento. Por um lado, esse discurso aparece como acesso a algo a que todos deveriam ter direito, como se fosse uma questão de igualdade. Por outro, contém a noção de reparação (como se fosse uma ação afirmativa, que atesta o discurso da diferença) pelos anos de internação. A política de reparação, como analisam Fassin e Rechtman (2007: 23), afirma o estado de vítima dos indivíduos, que procuram reivindicar a compensação de um prejuízo. A partir dessa reflexão é possível afirmar que no SRT o discurso político do sofrimento ${ }^{14}$ atesta as desigualdades a que estão submetidos os usuários e aciona um jogo tático o qual é invocado como um recurso, garantindo, dessa maneira, alguns direitos (caso do benefício, moradia e assistência). Esse discurso é um instrumento mobilizado a partir da inteligência dos profissionais.

Desse modo, produzir "qualidade de vida" e evitar o sofrimento são metas dos profissionais do SRT e formas de racionalização política, uma vez que justificam determinadas ações sobre o comportamento, o corpo e a vida daqueles. O sofrimento é considerado uma invenção e uma construção política, ao ser descrito por psiquiatras como o resultado de situações sociais (Fassin 2010: 61). Detectar o sofrimento significa transformá-lo em um índice capaz de calcular a subjetividade do usuário e fazer a sua gestão através da constatação de que uma necessidade ou um desejo podem ser administrados como algo a ser alcançado, como uma meta ou como um projeto de vida. Esse é o mecanismo

14 Destaco aqui a análise de Lacerda (2014), que aciona narrativas que explicitam o sofrimento de famílias que foram vítimas de violência como estratégia de ação política, e as reflexões de Das (1999) acerca do sofrimento decorrente de violência sofrida por mulheres no interior de famílias ou grupos de parentesco punjabi. 
operado no governo dos usuários no processo de reforma no SSCF desde a implementação do PTI, que codifica a subjetividade em termos de gestão e objetivos.

As práticas de governo funcionam, cada vez mais, por meio de mecanismos que alinham a conduta, os desejos e as decisões dos cidadãos com os objetivos institucionais (Rose 2011: 164), e, em sua agência, elas não utilizam protocolos fixos: acionam diferentes técnicas modeladas a partir da individualidade dos cidadãos, de forma a orientar (ou persuadir) suas escolhas. As ações guiadas por esse mecanismo "psi” estão imbricadas na produção de ações que levam em conta a liberdade, a autonomia e as escolhas daqueles a partir do conhecimento e das informações sobre suas motivações e relações, dissipando as resistências e tornando-os aliados das ações que os governam. Para tornar a subjetividade governável são necessárias informações apreendidas pelo "técnico de referência" (ou apenas "referência").

A produção do conhecimento sobre a individualidade é feita a partir de informações adquiridas na observação e na prática da escuta das demandas dos usuários. Para isso, os profissionais estabelecem um "vínculo" (ou uma relação de confiança) com aqueles em quem reconhecem uma afinidade. A relação de afinidade é um critério calculado quando o profissional se disponibiliza a ser técnico de referência, o mesmo que o responsável por conduzir o seu cuidado. O "referência" compromete-se a acompanhar, mesmo que, por vezes, à distância, o estado geral do usuário por meio das informações partilhadas por outros profissionais (a exemplo, se o usuário está participando do grupo de música, se está tomando a medicação ou se recebeu o resultado de um exame). O processo de deslocamento do espaço de tratamento para as moradias e a elaboração de novas estratégias de cuidado orientadas pela relação de "vínculo" resultou na necessidade de um profissional resiliente, ou seja, capaz de responder a situações incontingentes e/ou imprevisíveis, de identificar e criar estratégias para solucionar os problemas, de decidir a forma de agir em momentos de tensão e de avaliar suas ações para torná-las cada vez mais efetivas. Segundo uma interlocutora de pesquisa, médica psiquiatra que trabalhava no CAPS Esperança e atualmente é gestora de um CAPSi, a pessoa resiliente é proativa, ou seja, tem iniciativa e se antecipa na elaboração de ações estratégicas em situações de mudança.

A prática de cuidado, no SRT, além de administrar os aspectos psiquiátricos, clínicos, sociais e subjetivos, tem o objetivo de produzir condutas autônomas, relações de responsabilidade, formas de circulação e a conquista de direitos sociais como benefícios, moradia e lazer. As práticas de cuidado são ações que procuram garantir a segurança dos usuários, executando uma avaliação dos riscos e de uma sequência de fenômenos e acontecimentos que são prováveis (Castel 1987). Esse saber decorrente das probabilidades resulta em uma forma de gestão e controle das estimativas de tudo aquilo que pode acontecer. 
Ao procurar regular a probabilidade, desenvolve-se a análise dos elementos possíveis, combinados aos elementos aleatórios em um determinado meio.

As intervenções de cuidado apresentam o planejamento das condutas dos usuários, a avaliação de suas formas de atuação técnica e as problematizações como um processo de governo (Rose e Miller 2012: 25) que constrói um problema e o torna visível para a ação política. Nesse processo, a política, além de ser a instrumentalização das concepções acerca do que é necessário modificar para efetivar o processo de reforma institucional, é a maneira como as decisões avaliadas como prioridade para as mudanças são registradas em planos de intervenção.

\section{CONCLUSÃO}

No SRT, em 2011, a institucionalização da grande maioria dos moradores foi justificada a partir do argumento da sua precariedade social. A dependência institucional dos moradores decorria de sua situação de abandono familiar. Essa realidade evidenciava, por um lado, o papel da instituição no suprimento da ausência das relações familiares, com cuidados direcionados para o manejo da vida econômica, social e afetiva; por outro, os elementos singulares da história de cada morador, que autorizavam o governo institucional de sua vida a partir do argumento de que era vítima de desordens sociais e econômicas - portanto, era alvo de intervenções calculadas e elaboradas a partir do seu próprio testemunho autobiográfico (Fassin 2004: 259).

As práticas de governo, por sua vez, foram analisadas por meio dos enunciados dos profissionais sobre as intervenções de cuidado discutidas em equipe e formalizadas no documento do PTI, instrumento de registro das informações da história de vida e das demandas do usuário que expõe a sua subjetividade e as suas motivações em termos calculáveis. As informações que compõem a singularidade dos usuários são acionadas na fabricação de práticas de governo, as quais são justificadas por um- discurso que visa prevenir riscos. Desse modo, os profissionais inventam mecanismos para agir sobre a vida dos usuários e para direcioná-la aos seus propósitos institucionais, que não estão desconectados dos objetivos da reforma em seu modelo de assistência e que procuram atender às recomendações ministeriais descritas nas portarias.

As mudanças arquitetônicas, a organização da equipe e a emergência de um profissional resiliente foram adaptações institucionais que ocorreram para estabelecer uma assistência nas moradias transformadas em um dispositivo de saúde. As moradias não são somente um espaço de habitação, mas um serviço de saúde. 


\section{BIBLIOGRAFIA}

AMARANTE, Paulo, 1995, Loucos pela Vida: A Trajetória da Reforma Psiquiátrica no Brasil. Rio de Janeiro, Editora Fiocruz.

ANDRADE, Ana Paula Muller, e Sônia Weidner MALUf, 2016, "Sujeitos e(m) experiências: estratégias micropolíticas no contexto da reforma psiquiátrica no Brasil”, Physis: Revista de Saúde Coletiva, 26 (1): 251-270.

CANESQUI, Ana Maria, 2003, "Os estudos de antropologia da saúde/doença no Brasil na década de 1990", Ciência e Saúde Coletiva, 8 (1): 109-124.

CARDOSO, Marina Denise, 2002, "Psiquiatria e antropologia: notas sobre um debate inconcluso", Ilha: Revista de Antropologia, 4 (1): 85-113.

CARVALHO, Marcos, 2014, "Família no CAPS, família no território: etnografando encontros entre equipe profissional e familiares de usuários de um serviço de saúde mental", Ciências Humanas e Sociais em Revista, 36 (1): 68-80.

CASTEL, Robert, 1987, A Gestão dos Riscos: Da Antipsiquiatria à Pós-Psicanálise. Rio de Janeiro, Francisco Alves.

COLLIER, Stephen J., e Andrew LAKOFF, 2005, “On regimes of living”, em S. J. Collier e A. Ong (orgs.), Global Assemblages: Technology, Politics and Ethics as Anthropological Problems. Malden, MA, Blackwell Publishing, 22-39.

COMERFORD, John, 2001, "Reuniões camponesas, sociabilidades e lutas simbólicas”, em M. Peirano (org.), O Dito e o Feito: Ensaios de Antropologia dos Rituais. Rio de Janeiro, Relume Dumará, 149-168.

COOPER, David, 1973, Psiquiatria e Antipsiquiatria. São Paulo, Perspectiva.

DAS, Veena, 1999, "Fronteiras, violência e o trabalho do tempo: alguns temas wittgensteinianos", Revista Brasileira de Ciências Sociais, 14 (40): 31-42.

DIAS, Marcelo K., 2007, Centros de Atenção Psicossocial: Do Modelo Institucional à Experiência Social da Doença. Campinas, Universidade Estadual de Campinas, tese de doutorado em Ciências Sociais.

DUARTE, Luiz Fernando Dias, 1986, Da Vida Nervosa nas Classes Trabalhadoras Urbanas Brasileiras. Rio de Janeiro, Jorge Zahar Editor/CNPq.

FASSIN, Didier, 2004, "Le corps exposé: essai d'économie morale de l'illégitimité", em D. Fassin e D. Memmi (orgs.), Le gouvernement des corps. Paris, Editions de l'EHESS, 237 $-266$.

FASSIN, Didier, 2010, La raison humanitaire: une histoire morale du temps présent. Paris, Editions Gallimard/Seuil.

FASSIN, Didier, e Richard RECHTMAN, 2007, L'empire du traumatisme: enquête sur la condition de victime. Paris, Editions Flammarion.

FOUCAULT, Michel, 2004a, "O nascimento do hospital", em M. Foucault, Microfísica do Poder. Rio de Janeiro, Graal, 99-111.

FOUCAULT, Michel, 2004b, "Sobre a história da sexualidade", em M. Foucault, Microfísica do Poder. Rio de Janeiro, Graal, 243-276.

FOUCAULT, Michel, 2006, "A governamentalidade", em M. Foucault, Ditos e Escritos IV: Estratégia, Poder-Saber. Rio de Janeiro, Forense, 281-305 (2. ${ }^{a}$ edição).

FOUCAUlT, Michel, $2011 \mathrm{a}$, Do Governo dos Vivos: Curso no Collège de France, 1979-1980 - Excertos. São Paulo, Centro de Cultural Social/Rio de Janeiro, Achiamé (2. ${ }^{a}$ edição, revista e ampliada). 
FOUCAUlT, Michel, 201 lb, Nascimento da Biopolítica. São Paulo, Martins Fontes.

FURTADO, Juarez Pereira, 2001, "Responsabilização e vínculo no tratamento de pacientes cronificados: da unidade de reabilitação de moradores ao CAPS Estação”, em A. Harari e W. Valentini (orgs.), A Reforma Psiquiátrica no Cotidiano. São Paulo, Editora Hucitec, 37-58.

HIRATA, Daniel, e Bruno CARDOSO, 2016, "Coordenação como tecnologia de governo", Horizontes Antropológicos, 46: 97-130.

HIRATA, Helena, e Nadya Araujo GUimArÃES (orgs.), 2012, Cuidados e Cuidadoras: As Várias Faces do Trabalho do Care. São Paulo, Editora Atlas, 217-223.

LACERDA, Paula, 2014, "O sofrer, o narrar, o agir: dimensões da mobilização social de familiares de vítimas”, Horizontes Antropológicos, 42: 49-75.

LOUGON, Mauricio, 1987, Os Caminhos da Mudança: Alienados, Alienistas e a Desinstitucionalização da Assistência Psiquiátrica Pública. Rio de Janeiro, Universidade Federal do Rio de Janeiro, dissertação de mestrado em Antropologia Social.

LOVEll, Anne M., e Nancy SCHEPER-HUGHES, 1986, "Deinstitutionalization and psychiatric expertise: reflections on dangerousness, deviancy, and madness (Italy and the United States)", International Journal of Law and Psychiatry, 9 (3): 361-381.

MONNERAT, Silvia B., 2011 , "Sociabilidade como tratamento: estudo etnográfico de um centro de convivência para pacientes psiquiátricos", Tempus: Actas de Saúde Coletiva, 5 (2): 143-159.

NAKAMURA, Eunice, 2014, "Inserção social: dimensões e significados da vida sociocultural”, em Juarez Pereira Furtado e Eunice Nakamura (orgs.), Inserção Social e Habitação de Pessoas com Sofrimento Mental Grave. São Paulo, FAP/Unifesp, 65-83.

ONG, Aihwa, 2005, "Ecologies of expertise: assembling flows, managing citizenship", em S. J. Collier e A. Ong (orgs.), Global Assemblages: Technology, Politics and Ethics as Anthropological Problems. Malden, MA, Blackwell Publishing, 337-354.

PITIÁ, Ana Celeste Araújo, e Antônia Regina Ferreira FUREGATO, 2009, “O Acompanhamento Terapêutico (AT): dispositivo de atenção psicossocial em saúde mental”, Interface: Comunicação, Saúde, Educação, 13 (30): 67-77.

POLICARPO, Frederico, 2013, O Consumo de Drogas e Seus Controles: Uma Perspectiva Comparada entre as Cidades do Rio de Janeiro, Brasil, e de San Francisco, EUA. Niterói, Universidade Federal Fluminense, tese de doutorado em Antropologia.

PORTUGAL, Sílvia, Cláudia NOGUEIRA, e Pedro HESPANHA, 2014, "As teias que a doença tece: a análise das redes sociais no cuidado da doença mental", Dados: Revista de Ciências Sociais, 57 (4): 935-968.

PUSSETTI, Chiara, e Micol BRAZZABENI, 201 1, "Sofrimento social: idiomas da exclusão e políticas do assistencialismo”, Etnográfica, 15 (3): 467-478, DOI: 10.4000/etnografic a.1036 (última consulta em outubro de 2018).

ROLIM, Mônica Grant, 2013, "A questão da moradia em saúde mental”, em Mário Diniz Mateus (org.), Políticas de Saúde Mental. São Paulo, Instituto de Saúde, 169-175.

ROSE, Nikolas, 2011, Inventando Nossos Selfs: Psicologia, Poder e Subjetividade. Petrópolis, Vozes.

ROSE, Nikolas, e Paul MILler, 2012, Governando o Presente: Gerenciando a Vida Econômica, Social e Pessoal. São Paulo, Paulus.

SARTORI, Lecy, 2010, O Manejo da Cidadania em Um Centro de Atenção Psicossocial. São Carlos, Universidade Federal de São Carlos, dissertação de mestrado em Antropologia Social. 
SARTORI, Lecy, 2015, A Política de Financiamento de Uma Tecnologia de Cuidado: Etnografia do Processo de Reforma Psiquiátrica do Serviço de Saúde Dr. Cândido Ferreira. São Carlos, Universidade Federal de São Carlos, tese de doutorado em Antropologia Social.

SARTORI, Lecy, 2017, "Reabilitação psicossocial e produção de sujeitos: etnografia em um Serviço Residencial Terapêutico", Anais da VI Reunião de Antropologia da Ciência e da Tecnologia (ReACT), disponível em < https://ocs.ige.unicamp.br/ojs/react/article/view/2634 $/ 2374>$ (última consulta em outubro de 2018).

SILVA, Martinho B. B., 2013, "O que a Reforma Psiquiátrica Brasileira produziu? Sobre tecnologias psicossociais e categorias antimanicomiais", Revista de Antropologia da UFSCar, 5 (2): 57-68.

SIQUEIRA-SILVA, Raquel, João Arriscado NUNES, e Marcia Oliveira MORAIS, 2013, "Portugal e Brasil no cenário da saúde mental”, Fractal, 25 (3): 475-496.

SZASZ, Thomas, 1978, A Fabricação da Loucura: Um Estudo Comparativo entre a Inquisição e o Movimento de Saúde Mental. Rio de Janeiro, Jorge Zahar Editor.

SZASZ, Thomas, 1979, O Mito da Doença Mental. Rio de Janeiro, Jorge Zahar Editor.

TAVARES, Fátima, Carlos CAROSO, e Carolina SANTANA, 2015, "Mediações do cuidado no âmbito do Programa Saúde da Família em Itaparica, Brasil”, Etnográfica, 19 (3): 489-513, DOI: 10.4000/etnografica.4085 (última consulta em outubro de 2018).

VENÂNCIO, Ana T.A., 1990, Sobre a "Nova Psiquiatria" no Brasil: Um Estudo de Caso do Hospital-Dia do Instituto de Psiquiatria. Rio de Janeiro, Universidade Federal do Rio de Janeiro, dissertação de mestrado em Antropologia Social.

VENÂNCIO, Ana T.A., 1993, "A construção social da pessoa e a psiquiatria: do alienismo à 'nova psiquiatria'", Physis: Revista de Saúde Coletiva, 3 (2): 1 17-135.

ZELIZER, Viviane, 2012, "A economia do care", em H. Hirata e N.A. Guimarães (orgs.), Cuidados e Cuidadoras: As Várias Faces do Trabalho do Care. São Paulo, Editora Atlas, 15-28. 